\title{
Estimation of the incidence of severe fever with thrombocytopenia syndrome in high endemic areas in China: an inpatient-based retrospective study
}

Xiaoxia Huang ${ }^{1 \dagger}$, Shiwen Wang ${ }^{1+}$, Xianjun Wang ${ }^{2 \dagger}$, Yong Lyu ${ }^{3 \dagger}$, Mei Jiang ${ }^{4}$, Deying Chen ${ }^{5}$, Kaichun Li ${ }^{3}$, Jingyu Liu ${ }^{4}$, Shaoyu Xie ${ }^{3}$, Tao Lyu ${ }^{5}$, Jie Sun ${ }^{3}$, Pengpeng $\mathrm{Xu}^{3}$, Minghua Cao ${ }^{6}$, Mifang Liang ${ }^{1}$ and Dexin $\mathrm{Li}^{i^{*}}$

\begin{abstract}
Background: Severe fever with thrombocytopenia syndrome (SFTS) is a severe viral disease caused by SFTSV. It is important to estimate the rate of missed SFTS diagnosis and to further understand the actual incidence in high endemic areas in China.

Methods: This study was conducted in two high SFTS endemic provinces in 2015. Patients hospitalized in 2014 or within 1 year before investigation were selected after considering their clinical manifestations, specifically, fever, platelet, and white blood cell. During retrospective investigation, sera were collected to detect SFTSV antibodies to assess SFTSV infection. To further understand SFTSV infection, acute phase sera were detected; SFTSV infection rate among a healthy population was also investigated to determine the basic infection level.

Results: In total, 246 hospitalized cases were included, including 83 cases (33.7\%) with fever, thrombocytopenia and leukopenia, 38 cases (15.4\%) with fever and thrombocytopenia but without leukopenia, and 125 cases (50.8\%) without fever but with thrombocytopenia and leukopenia. In total, 13 patients (5.3\%) were SFTSV IgM antibody-positive, 48 (19.5\%) were lgG-positive. Of the $13 \mathrm{lgM}$-positive cases, 11 (84.6\%) were lgG-positive (9 with titres $\geq 1: 400$ ). Seropositive rates of antibodies were high (8.4\% for lgM and $30.1 \%$ for $\operatorname{lgG}$ ) in patients with fever, thrombocytopenia and leukopenia. Furthermore, among lgG-positive cases in this group, 76\% (19/25) of patients' lgG antibody titres were $\geq 1: 400$. Additionally, 28 of 246 cases were initially diagnosed with suspected SFTS and were then excluded, and 218 patients were never diagnosed with SFTS; the seropositive rates of $\mathrm{IgM}$ and $\operatorname{lgG}$ in these two groups were $25 \%$ and $67.9 \%$ and $2.8 \%$ and $13.3 \%$, respectively. These rates were $64.3 \%$ and $21.4 \%$ in 14 sera collected during acute phase of the 28 cases mentioned above. Seropositive rate of SFTSV IgG was only $1.3 \%$ in the patient-matched healthy group, and no IgM antibody was detected. A preliminary estimate of 8.3\% of SFTS cases were missed in SFTS high endemic provinces.
\end{abstract}

Conclusions: The actual SFTS incidence was underestimated. Effective measures such as adding a new SFTS case category - "SFTS clinical diagnosis cases" or using serological detection methods during acute phase should be considered to avoid missed diagnoses.

Keywords: SFTS, SFTSV antibodies, Missed diagnosis, SFTS incidence

\footnotetext{
* Correspondence: lidx@chinacdc.cn

${ }^{\dagger}$ Equal contributors

${ }^{1}$ National Institute for Viral Disease Control and Prevention, Chinese Center for Disease Control and Prevention, 155 Changbai Road, Changping District, Beijing 102206, People's Republic of China

Full list of author information is available at the end of the article
} 


\section{Background}

Severe fever with thrombocytopenia syndrome (SFTS) is a newly discovered infectious disease that was reported in 2009 in two provinces of central China and had a $7.9 \%$ fatality rate $[1,2]$. Thereafter, the SFTS case number increased annually [2]. With the expansion in endemic areas, 25 provinces reported having more than 10,000 SFTS cases by 2016. SFTS virus (SFTSV), a novel member of the Phlebovirus genus of the Phenuiviridae family, was identified to be its pathogen [1]. SFTSV can be transmitted by tick bites [3, 4]. Person-to-person transmission through blood or body fluid contact was also an important transmission route and caused multiple cluster cases in several provinces [5-12]. Because of the high mortality and person-to-person transmission, SFTS has become a serious threat to public health.

In China, more than $85 \%$ of SFTS cases are farmers living in seven provinces (Henan, Shandong, Hubei, Anhui, Liaoning, Zhejiang, and Jiangsu) [2]. The clinical manifestations of SFTS vary from mild symptoms to death $[2,4,13,14]$, although they mainly include fever, thrombocytopenia, leukopenia, and gastrointestinal symptoms; disseminated intravascular coagulation and multi-organ failure can occur in some severe cases $[1,4$, 15-17]. A small portion of SFTS cases have a definitive history of a tick bite [18] and lymphadenopathy [1]. SFTS needs to be identified with other infectious diseases (haemorrhagic fever with renal syndrome, human anaplasmosis, leptospirosis, and septicaemia,) and noninfectious diseases (thrombocytolytic purpura) [1, 15].

In China, SFTS cases are officially divided into two categories: suspected cases and lab-confirmed cases [15]. In 2010, SFTS surveillance was conducted to understand its epidemic characteristics, and this surveillance was very important for providing basic epidemic data for SFTS prevention and control. However, accurate monitoring data depend on accurate disease diagnoses. Previous studies have shown that missed diagnoses [19-21] exist in many infectious diseases such as hepatitis B, measles, and rubella. However, the occurrence of missed diagnosis in SFTS was unclear. Therefore, we conducted this study to obtain rudimentary knowledge of SFTS missed diagnosis and to further understand the actual incidence of SFTS by studying the epidemiological features, clinical manifestations, and presence of antibodies against SFTSV in hospitalized patients.

\section{Methods}

\section{Study sites}

This study was conducted in two high SFTS endemic provinces. For confidentiality, we used "place1" and "place2" to represent these two provinces. In total, eight hospitals in these areas were selected to be included in this study. Moreover, an area that had no reported cases of SFTS before this investigation was selected as a control site to determine the SFTSV prevalence in a healthy population.

\section{SFTS case definition}

According to the "Guideline for SFTS prevention and control (2010)" [15] issued by the National Health and Family Planning Commission of the People's Republic of China, SFTS cases were divided into two categories: suspected cases and lab-confirmed cases. The diagnostic criteria for suspected cases included the following: an epidemiologic history (i.e., working, living or traveling in the hills, forest or mountain in SFTS epidemic season or being bitten by ticks within 2 weeks before disease onset) and clinical manifestations, such as fever and decrease in platelets and white blood cells in peripheral blood. Lab-confirmed SFTS cases were defined as suspected cases with at least one positive laboratory test (SFTSV RNA detected, seroconversion or four-fold increase in SFTSV IgG antibody or SFTSV isolated from specimens).

\section{Study subjects}

In this study, subjects were required to be hospitalized patients in 2014 or within 1 year before the investigation and to have clinical characteristics in the following groups:

1) Fever $\left(>37.3^{\circ} \mathrm{C}\right)$ with thrombocytopenia $\left(<100^{*} 10^{9} / \mathrm{L}\right)$ and leukopenia $\left(<4 * 10^{9} / \mathrm{L}\right)$;

2) Fever $\left(>37.3^{\circ} \mathrm{C}\right)$ with thrombocytopenia $\left(<100^{*} 10^{9} / \mathrm{L}\right)$ and without leukopenia $\left(<4 * 10^{9} / \mathrm{L}\right)$; or

3) Thrombocytopenia $\left(<100 * 10^{9} / \mathrm{L}\right)$ and leukopenia $\left(<4^{*} 10^{9} / \mathrm{L}\right)$ without fever $\left(>37.3^{\circ} \mathrm{C}\right)$.

If patients with the above characteristics were definitively diagnosed with immune or blood diseases (such as septicaemia and thrombocytolytic purpura) or were labconfirmed SFTS cases, they were excluded from this study. Furthermore, the subjects were also required to be healthy during the retrospective investigation.

\section{Epidemiologic and clinical data collection}

A retrospective survey was conducted with a constructed questionnaire designed to collect demographic information and exposure history. Clinical characteristics including time of disease onset, clinical diagnosis, body temperature, platelet (PLT) and white blood cell (WBC) counts, alanine aminotransferase (ALT), aspartate transaminase (AST), lactate dehydrogenase (LDH), and creatine kinase $(\mathrm{CK})$ were retrieved from patients' medical records. 


\section{Sample collection and detection}

During the investigation, blood samples were collected from the study subjects (including children participants) and sera were separated. Additionally, sera samples that had been collected from the subjects during hospitalization were analysed using SFTSV antibody and RNA tests. Enzyme-linked immunosorbent assay kits (Zhongshan biotech CO., LTD.) were used to detect antibodies (IgM and IgG) against SFTSV and to quantify IgG titres as described in the instructions. According to the detection instructions, $100 \mu \mathrm{l}$ diluted sera $(10 \mu \mathrm{l}$ sera in $90 \mu \mathrm{l}$ sample dilution for IgM detection, $1 \mu \mathrm{l}$ sera diluted in $100 \mu \mathrm{l}$ sample dilution for IgG detection) were added to each well and were incubated at $37{ }^{\circ} \mathrm{C}$ for $30-40 \mathrm{~min}$. After washing, $100 \mu \mathrm{l}$ horseradish peroxidase (HRP) - labelled reagent was placed in each well and incubated at $37{ }^{\circ} \mathrm{C}$ for $30-40 \mathrm{~min}$. Then, chromogenic agents were added to develop colour change. After incubation, the optical density (OD) value was read at $450 \mathrm{~nm}$. For every detection or plate, two negative and two positive controls were set. Based on an equation described previously [22], the cutoff value was calculated. A SFTSV IgM- or IgG-positive sample was defined as a sample with an $\mathrm{OD}$ value greater than or equal to the cutoff value. SFTSV RNA was detected by real-time reverse transcription-polymerase chain reaction (RT-PCR) method, as previously described [1].

\section{Statistical analysis}

Statistical analysis was performed by SPSS 18.0 (Chicago, IL, USA), and the statistical significance was set at $p<0.05$. Chi-square test (Pearson Chi-square or Fisher's exact test) was used to analyse count data to compare the clinical manifestations and SFTSV antibody-positive rate in different groups.

\section{Results}

\section{Hospitalized patients' information}

A total of 246 hospitalized patients were included in this study, including 83 cases (33.7\%) with fever, thrombocytopenia and leukopenia, 38 cases (15.4\%) with fever and thrombocytopenia but without leukopenia, and 125 patients (50.8\%) without fever but with thrombocytopenia and leukopenia. Of the 246 hospitalized cases, 130 (52.8\%) were male; the largest proportion, 180 $(73.2 \%)$, were farmers, followed by retirees $(17,6.9 \%)$ and household workers and unemployed (17, 6.9\%); 165 (69\%) lived in hilly or mountainous areas and $62(25.9 \%)$ in the plains; and the median age was 64 years (range 2-93 years).

Of these subjects, 28 (11.4\%) were initially diagnosed as SFTS-suspected cases and were then excluded. Records of 24 cases showed that the reason for exclusion was negative detection of SFTSV RNA. The other 218 (88.6\%) cases were never diagnosed as SFTS cases.

\section{Laboratory detection}

Sera were collected from all 246 cases during the investigation. The median (interquartile range) days of specimen collection after disease onset was 346 d (250-484 d). In total, $50(20.3 \%)$ cases were SFTSV antibody-positive, including 13 (5.3\%) IgM-positive and 48 (19.5\%) IgG-positive (the detailed SFTSV antibody detection results were showed in Additional file 1). Of the 13 IgM-positive cases, $11(84.6 \%)$ were IgG-positive ( 9 with titres $\geq 1: 400,2$ with titres equal to 1:100). Two specimens with IgG antibody against SFTSV (titres equal to 1:100) were identified in the serum samples of 150 patient-matched healthy control subjects from SFTS non-endemic areas, and no IgM was detected. The seropositive rates of antibodies were very high $(8.4 \%$ for IgM and $30.1 \%$ for IgG) in patients with fever, thrombocytopenia and leukopenia (Fig. 1). Furthermore, among the IgG-positive cases in this group, 76\% $(19 / 25)$ of patients' IgG antibody titres were greater than or equal to 1:400 (Table 1).

Of the 28 patients who were excluded from the SFTS cases, $19(67.9 \%)$ were IgG antibody seropositive, and the titres of $84.2 \%(16 / 19)$ IgG-positive cases were $\geq 1: 400 ; 7$ cases $(25 \%)$ were both IgM and IgG antibody-positive. There was a significant difference between these 28 patients and healthy persons in the seropositive rate of IgG antibody $\left(x^{2}=100.347, p=0.000\right)$. Of the 218 patients who had

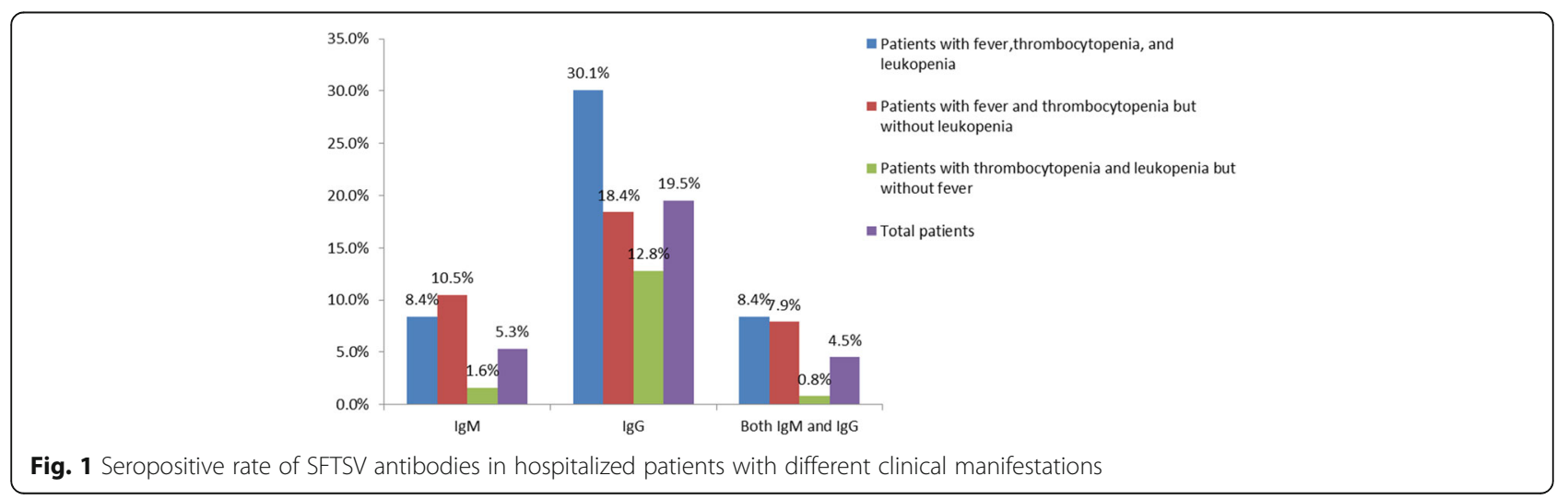


Table 1 SFTSV IgG antibody titres in hospitalized patients with different clinical manifestations

\begin{tabular}{llll}
\hline SFTSV-IgG titre (1:) & $\begin{array}{l}\text { Patients with fever, } \\
\text { thrombocytopenia, } \\
\text { and leukopenia }(N=83) \\
\mathrm{n}(\%)\end{array}$ & $\begin{array}{l}\text { Patients with fever } \\
\text { and thrombocytopenia } \\
\text { but without leukopenia }(N=38) \\
\mathrm{n}(\%)\end{array}$ & $\begin{array}{l}\text { Patients with thrombocytopenia } \\
\text { and leukopenia but without fever }(N=125) \\
\mathrm{n}(\%)\end{array}$ \\
\hline 6400 & $0(0)$ & $0(0)$ & $0(0)$ \\
1600 & $6(7.2)$ & $2(5.3)$ & $0(0)$ \\
400 & $13(15.7)$ & $2(5.3)$ & $4(3.2)$ \\
100 & $6(7.2)$ & $3(7.9)$ & $12(9.6)$ \\
Total & $25(30.1)$ & $7(18.5)$ & $16(12.8)$ \\
\hline
\end{tabular}

never been diagnosed with SFTS, 29 (13.3\%) were IgG antibody-positive, and $37.9 \%(11 / 29)$ of the seropositive specimens had IgG titres $\geq 1: 400 ; 6$ cases $(2.8 \%)$ were IgM antibody-positive, and 4 of them were both IgM and IgG antibody-positive. Table 2 showed the results of the SFTSV antibodies and titres in hospitalized patients with different clinical diagnoses.

Sera samples collected during hospitalization were found for 14 hospitalized patients. The median age of these patients was 58 years old (range 27-81 years), and 7 (50\%) were female. The median collection day after disease onset was 9 days. SFTSV RNA was not detected. The seropositive rates of SFTSV IgM, IgG, and the two antibodies simultaneously were $64.3 \%$ (9/14), 21.4\% (3/14), and $14.3 \%(2 / 14)$, respectively. The 8 seropositive specimens of IgM had IgG antibody titres greater than or equal to $1: 400$ in the convalescent stage. The titres of IgG antibody against SFTSV were not higher than 100 in serum samples from the acute phase. Four-fold elevation of SFTSV IgG antibody titres or seroconversion was observed in $71.4 \%(10 / 14)$ of patients. Table 3 showed detailed information on these 14 cases.

\section{SFTS incidence estimation}

The above results indicated that some patients' diagnoses were missed. We speculated that the 27 patients (11\%, 27/246) with IgG antibody titres greater than or equal to 1:400 in the retrospective study were most likely misdiagnosed. These patients did not significantly differ in major clinical signs (lymphadenopathy, WBC, AST, ALP, and LDH) from lab-confirmed SFTS cases (Table 4) [1]. Furthermore, 33.3\% of 27 cases were also IgM-positive. Therefore, we estimated that the missed diagnosis rate was approximately $8.3 \%$ in high SFTS endemic areas (Table 5). Based on this finding, the actual SFTS incidence in high endemic areas is much higher than the current reporting number.

\section{Discussions}

SFTS was first reported in mainland China 7 years ago as a highly pathogenic disease. In 2010, China developed "guidelines for SFTS prevention and control (2010)" [15] to standardize the case diagnosis and report. Because of the limitations in early understanding of SFTS, missed diagnoses may exist. Therefore, we conducted this study to address these missed cases. Our results showed that an estimated $8.3 \%$ of SFTS diagnoses were missed in high endemic areas of China. According to this result, the actual incidence of SFTS is much higher than the currently reported level.

In this study, we chose two provinces as our study areas based on the following reasons. First, these two provinces were both high SFTS endemic areas. The total number of SFTS cases in these regions between 2011 and 2014 were 1074 and 458 [2], respectively. Second, these two provinces had very different SFTS types. The proportions of lab-confirmed cases, clinically diagnosed cases (although this classification was not officially defined), and suspected cases were $70.9 \%, 25.2 \%$, and $3.9 \%$ in one province and $39.1 \%, 55.0 \%, 5.9 \%$ in the other, respectively [2]. Therefore, these differences might provide more information about SFTS diagnosis for this study. In this study, we just selected a site, locating in low incidence area in place1 and being adjacent to some of the study sites, to understand the most basic level of SFTSV infection. SFTS was mainly characterized by

Table 2 SFTSV antibodies in hospitalized patients with different clinical diagnoses

\begin{tabular}{|c|c|c|c|c|c|c|c|c|}
\hline \multirow[t]{2}{*}{ Diagnosis during hospitalization } & \multirow[t]{2}{*}{ No. detected } & \multirow{2}{*}{$\begin{array}{l}\text { Seropositivity of IgM } \\
\mathrm{n}(\%)\end{array}$} & \multirow{2}{*}{$\begin{array}{l}\text { Seropositivity of lgG } \\
n(\%)\end{array}$} & \multicolumn{5}{|c|}{ Titres of $\lg G(1:) n(\%)$} \\
\hline & & & & 6400 & 1600 & 400 & 100 & $\langle 100$ \\
\hline Patients who were not diagnosed with SFTS & 218 & $6(2.8)$ & $29(13.3)$ & $0(0)$ & $2(0.9)$ & $9(4.1)$ & 18(8.3) & 189(86.7) \\
\hline $\begin{array}{l}\text { Patients who were initially diagnosed as } \\
\text { SFTS-suspected cases and then excluded }\end{array}$ & 28 & $7(25)$ & 19(67.9) & $0(0)$ & $6(21.4)$ & $10(35.7)$ & $3(10.7)$ & $9(32.1)$ \\
\hline Total & 246 & $13(5.3)$ & $48(19.5)$ & $0(0)$ & 8(3.3) & 19(7.7) & $21(8.5)$ & 198(80.5) \\
\hline
\end{tabular}


Table 3 Clinical manifestations and SFTSV antibody detection results in the 14 hospitalized cases

\begin{tabular}{|c|c|c|c|c|c|c|c|c|c|c|c|c|c|c|}
\hline Case No. & Gender & Lymphadenopathy & WBC & ALT & AST & CK & ALP & $\mathrm{LDH}$ & Days after onset ${ }^{(A P)}$ & $\lg \mathrm{M}^{(\mathrm{AP})}$ & $\lg G^{(A P)}$ & Days after onset ${ }^{(\mathrm{CP})}$ & $\lg M^{(C P)}$ & $\lg G^{(C P)}$ \\
\hline 1 & $F$ & $\mathrm{~N}$ & $L$ & $\mathrm{H}$ & $\mathrm{H}$ & $\mathrm{N}$ & $\mathrm{N}$ & $\mathrm{H}$ & 35 & $>10$ & 100 & 320 & $<10$ & 1600 \\
\hline 2 & F & $\mathrm{N}$ & $\mathrm{N}$ & $\mathrm{H}$ & $\mathrm{H}$ & $\mathrm{H}$ & $\mathrm{N}$ & $\mathrm{H}$ & 3 & $<10$ & 100 & 290 & $<10$ & 100 \\
\hline 3 & $F$ & N & L & $\mathrm{N}$ & $\mathrm{N}$ & - & N & $\mathrm{H}$ & 5 & $<10$ & $<100$ & 282 & $<10$ & $<100$ \\
\hline 4 & $\mathrm{~F}$ & $N$ & L & $\mathrm{H}$ & $\mathrm{N}$ & $\mathrm{N}$ & $\mathrm{N}$ & $\mathrm{N}$ & 5 & $<10$ & $<100$ & 313 & $<10$ & $<100$ \\
\hline 5 & M & $\mathrm{N}$ & L & $\mathrm{H}$ & $\mathrm{H}$ & $\mathrm{H}$ & N & $\mathrm{H}$ & 1 & $>10$ & $<100$ & 386 & $<10$ & 400 \\
\hline 6 & M & $\mathrm{N}$ & $\mathrm{N}$ & $\mathrm{H}$ & $\mathrm{H}$ & $\mathrm{H}$ & $\mathrm{H}$ & $\mathrm{H}$ & 13 & $>10$ & $<100$ & 407 & $>10$ & 1600 \\
\hline 7 & $M$ & $N$ & $N$ & $\mathrm{H}$ & $\mathrm{H}$ & $\mathrm{H}$ & $\mathrm{N}$ & $\mathrm{H}$ & 17 & $>10$ & $<100$ & 410 & $>10$ & 400 \\
\hline 8 & $F$ & Y & $\mathrm{L}$ & $\mathrm{N}$ & $\mathrm{H}$ & $\mathrm{N}$ & $\mathrm{N}$ & $\mathrm{N}$ & 4 & $<10$ & $<100$ & 373 & $<10$ & 100 \\
\hline 9 & $M$ & $\mathrm{~N}$ & L & $\mathrm{H}$ & $\mathrm{H}$ & $\mathrm{H}$ & L & $H$ & 9 & $>10$ & $<100$ & 423 & $<10$ & 400 \\
\hline 10 & $\mathrm{~F}$ & Y & L & $\mathrm{H}$ & $\mathrm{H}$ & $\mathrm{H}$ & $\mathrm{N}$ & $\mathrm{H}$ & 9 & $>10$ & $<100$ & 470 & $<10$ & 400 \\
\hline 11 & $M$ & $N$ & L & $\mathrm{H}$ & $\mathrm{H}$ & $\mathrm{H}$ & $\mathrm{N}$ & $\mathrm{H}$ & 12 & $>10$ & $<100$ & 473 & $<10$ & 100 \\
\hline 12 & $F$ & $\mathrm{~N}$ & L & $\mathrm{H}$ & $\mathrm{H}$ & $\mathrm{H}$ & $\mathrm{N}$ & $\mathrm{H}$ & 12 & $>10$ & 100 & 478 & $<10$ & 400 \\
\hline 13 & M & $\mathrm{N}$ & L & $\mathrm{H}$ & $\mathrm{H}$ & $\mathrm{H}$ & $N$ & $\mathrm{H}$ & 15 & $>10$ & $<100$ & 482 & $>10$ & 400 \\
\hline 14 & M & $\mathrm{N}$ & $\mathrm{N}$ & $\mathrm{N}$ & $\mathrm{N}$ & $\mathrm{N}$ & $\mathrm{N}$ & $\mathrm{N}$ & 5 & $<10$ & $<100$ & 551 & $<10$ & $<100$ \\
\hline
\end{tabular}

$F$ female, $M$ male, $N$ no or normal, $Y$ yes, $L$ low, $H$ high, $A P$ acute phase of disease, $C P$ convalescent phase of disease

fever, thrombocytopenia and leukopenia, especially the former two [1,23]. To make the study more targeted, all the subjects in our study had thrombocytopenia. Meanwhile, considering the presence of mild cases, we included patients without fever in this investigation.

The SFTSV IgG seropositive rate $(20.5 \%)$ in all subjects, especially in patients with fever, thrombocytopenia and leukopenia (30.1\%), was higher than the rate reported in high endemic areas in healthy people; for example, these rates were $7.2 \%$ in Zhejiang province [14], 6.6\% in Xinyang, Henan province [24], 5\% in Macheng, Hubei province [25], $4.7 \%$ in the western region of Anhui province [26], 3.3\% in Laizhou, Shandong province [27], and $0.4 \%$ in seven counties of Jiangsu province [28]. We found that the IgM positive rate was also high, which was not observed in healthy people [25]. Additionally, $69.2 \%$ of SFTSV IgM-positive cases had IgG titres $\geq 1: 400$.

A high seroprevalence (67.9\% for IgG, $25 \%$ for IgM) was observed in the 28 hospitalized patients (initially diagnosed as suspected SFTS cases and then excluded). Of these patients, $57.1 \%$ had IgG antibody titres greater than or equal to $1: 400$. In addition, $64.3 \%$ of the 14 sera collected in the acute phase were SFTSV IgM-positive, and this rate was similar to that described in labconfirmed SFTS cases $[29,30]$. This phenomenon

Table 4 Comparison of characteristics between the estimated missed diagnosis cases and lab-confirmed cases

\begin{tabular}{|c|c|c|c|}
\hline Characteristic & $\begin{array}{l}\text { Missed SFTS } \text { cases }^{c} \\
\text { no. / total no. (\%) }\end{array}$ & $\begin{array}{l}\text { Lab-confirmed SFTS cases } \\
\text { no. / total no. }(\%)\end{array}$ & $p$-value \\
\hline$\overline{\text { Age }(y r)^{a}}$ & 27/59(35-83) & / & / \\
\hline Male & 19/27(70.4) & / & / \\
\hline Farmer & 24/27(88.9) & / & / \\
\hline Hills or mountains & 25/27(92.6) & / & / \\
\hline Fever & 23/27(85.2) & 100/100(100) & 0.002 \\
\hline Lymphadenopathy & $6 / 23(26.1)$ & 23/81(28.4) & 0.828 \\
\hline WBC decreasing & 23/27(85.2) & $64 / 74(86.5)$ & 0.867 \\
\hline ALT elevation & $18 / 27(66.7)$ & $53 / 64(82.8)$ & 0.040 \\
\hline AST elevation & 24/27(88.9) & $59 / 63(93.7)$ & 0.440 \\
\hline ALP elevation & 1/26(3.8) & $3 / 53(5.7)$ & 1.000 \\
\hline LDH elevation & 22/26(84.6) & 49/51(96.1) & 0.171 \\
\hline CK elevation & 18/23(78.3) & 25/49(51) & 0.028 \\
\hline
\end{tabular}

a Presented as the median age and the range of age

${ }^{b}$ Characteristics of lab-confirmed SFTS cases were retrieved from a published article [1]

/:No data

${ }^{\mathrm{C}}$ Patients with IgG titres $\geq 1: 400$ were considered missed SFTS cases 
Table 5 Estimated missed diagnosis rate of SFTS

\begin{tabular}{llll}
\hline Study sites & No. SFTS cases during investigation & No. missed SFTS cases $^{\mathrm{a}}$ & Estimated missed diagnosis rate $^{\mathrm{b}}$ \\
\hline place1 & 195 & 19 & $8.9 \%$ \\
place2 & 104 & 8 & $7.1 \%$ \\
& 299 & 27 & $8.3 \%$
\end{tabular}

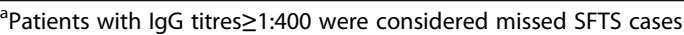

${ }^{\mathrm{b}}$ Missed diagnosis rate $=$ No. missed cases $/($ No. missed cases + No. SFTS cases during the investigation $) \times 100 \%$

suggested that some diagnoses of SFTS cases might be missed because of an over-reliance on laboratory test results [2]. SFTSV RNA test by real time RT-PCR was the most commonly used method for confirmation of recent SFTSV infection [1, 29]. However, many factors such as a long specimen collection time after disease onset [30-32], poor specimen and preservation condition, unskilled operation, and low virus load can lead to a low detection of viral RNA. Furthermore, of the 218 hospitalized patients who were never diagnosed with SFTS, 13.3\% were IgG-positive and 2.8\% IgM-positive; 13.7\% of IgG-positive specimens were positive for IgM. A small portion cases had IgG titres $\geq 1: 400$. We speculated that the diagnoses of these patients may have been missed because of their mild or subclinical manifestations [14]. So we suggested the use of serological detection methods during acute phase also, in order to increase the diagnostic sensibility for SFTS.

In our study, 27 of 246 hospitalized patients in our study were considered to be missed cases in light of their high IgG titres, high IgM-positive rate and the similarity of their clinical characteristics with lab-confirmed SFTS cases. An estimated 8.3\% of SFTS diagnoses in study sites were missed. However, our study was a preliminary study on missed diagnosis and the estimation was conservative. Further studies should be conducted to understand the reasons for these missed cases to implement measures (such as adding a new SFTS case category - "SFTS clinical diagnosis cases" or using serological detection methods during acute phase) to prevent missed diagnoses.

Current studies have shown that SFTSV IgM and IgG antibodies can still be detected 1.3 years and over 3 years after SFTSV infection [33, 34], respectively. In addition, detection of sera antibodies can be an alternative or supplement for later-collected specimen due to their later appearance than viremia [31]. However, several limitations of this study should be clarified. First, most of the specimens collected during the retrospective investigation were 6 months to 1.5 years after disease onset. SFTSV antibodies in some specimens may disappear or the titres may decrease [33], which can affect the antibody-positive rate. Second, we focused on high SFTS endemic provinces only; other non-endemic or low endemic provinces were not involved because of the time constraints. Accordingly, the analysis of missed SFTS diagnosis in China was not comprehensive. In further studies, the analysis should include other areas.

\section{Conclusions}

In conclusion, by analysing the clinical manifestations, epidemiological data, and SFTSV infection of hospitalized patients, our study preliminarily estimated a rate of missed SFTS diagnosis. The results showed that the SFTS incidence was much higher than the currently reported level. Reclassification of SFTS case types and improvements in detection capacity should be highlighted to ensure better SFTS prevention and control.

\section{Additional file}

Additional file 1: SFTSV antibody detection results of 246 patients. The detailed IgM and IgG antibody OD value of sera collected from 246 patients were showed in this Additional file 1. (XLSX $26 \mathrm{~kb}$ )

\section{Abbreviations}

ALT: Alanine aminotransferase; AP: Acute phase of disease; AST: Aspartate transaminase; CK: Creatine kinase; CP: Convalescent phase of disease; HRP: Horseradish peroxidase; LDH: Lactate dehydrogenase; OD: Optical density; PLT: Platelet; RT-PCR: Reverse transcription-polymerase chain reaction; SFTS: Severe fever with thrombocytopenia syndrome; SFTSV: SFTS virus; WBC: White blood cell

\section{Acknowledgements}

The authors thank the involved staff at the hospitals and local centers for disease control and prevention in Yantai city, Weihai city, and Luan city for their data and specimens collection.

\section{Funding}

This work was supported by the China Mega-Project for Infectious Diseases (2017ZX10101001) and National Science and Technology Support Program (2014BAl13B05).

\section{Availability of data and materials}

All data generated or analysed during this study are included in this published article and its additional information file.

\section{Authors' contributions}

Study design:DL, XH, SW, ML. Data and specimen collection: XW, YL, MJ, DC, $K L, J L, S X, T L, J S, P X, M C$. Experiments and data analysis: XH, XW, YL. Writing: $\mathrm{XH}, \mathrm{SW}, \mathrm{DL}$. All authors read and approved the final manuscript.

\section{Ethics approval and consent to participate}

The study was approved and consented by Ethics Committee of National Institute for Viral Disease Control and Prevention, China CDC. Written informed consent was obtained from adult participants and the legal guardian of the children participants.

Consent for publication

Not applicable.

Competing interests

The authors declare that they have no competing interests. 


\section{Publisher's Note}

Springer Nature remains neutral with regard to jurisdictional claims in published maps and institutional affiliations.

\section{Author details}

${ }^{1}$ National Institute for Viral Disease Control and Prevention, Chinese Center for Disease Control and Prevention, 155 Changbai Road, Changping District, Beijing 102206, People's Republic of China. ${ }^{2}$ Shandong Center for Disease Control and Prevention, Jinan, Shandong Province, People's Republic of China. ' ${ }^{3}$ Lu'an Center for Disease Control and Prevention, Lu'an, Anhui Province, People's Republic of China. ${ }^{4}$ Yantai Center for Disease Control and Prevention, Yantai, Shandong Province, People's Republic of China. ${ }^{5}$ Weihai Center for Disease Control and Prevention, Weihai, Shandong Province, People's Republic of China. ${ }^{6}$ Anhui Center for Disease Control and Prevention, Hefei, Anhui Province, People's Republic of China.

\section{Received: 6 June 2017 Accepted: 18 January 2018}

Published online: 05 February 2018

\section{References}

1. Yu XJ, Liang MF, Zhang SY, Liu Y, Li JD, Sun YL, Zhang L, Zhang QF, Popov VL, Li C, et al. Fever with thrombocytopenia associated with a novel bunyavirus in China. N Engl J Med. 2011;364(16):1523-32.

2. Li Y, Zhou H, Mu D, Yin W, Yu H. Epidemiological analysis on severe fever with thrombocytopenia syndrome under the national surveillance data from 2011 to 2014, China. Zhonghua Liu Xing Bing Xue Za Zhi. 2015;36(6):598-602.

3. Xing X, Guan X, Liu L, Zhan J, Jiang H, Li G, Xiong J, Tan L, Xu J, Jiang Y, et al. Natural transmission model for severe fever with thrombocytopenia syndrome Bunyavirus in villages of Hubei Province, China. Medicine. 2016;95(4):e2533.

4. Li DX. Severe fever with thrombocytopenia syndrome: a newly discovered emerging infectious disease. Clin Microbiol Infect. 2015;21(7):614-20.

5. Bao CJ, Guo XL, Qi X, Hu JL, Zhou MH, Varma JK, Cui LB, Yang HT, Jiao YJ, Klena JD, et al. A family cluster of infections by a newly recognized bunyavirus in eastern China, 2007: further evidence of person-to-person transmission. Clin Infect Dis. 2011;53(12):1208-14.

6. Gai Z, Liang M, Zhang Y, Zhang S, Jin C, Wang SW, Sun L, Zhou N, Zhang Q, Sun $Y$, et al. Person-to-person transmission of severe fever with thrombocytopenia syndrome bunyavirus through blood contact. Clin Infect Dis. 2012;54(2):249-52.

7. Liu Y, Li Q, Hu W, Wu J, Wang Y, Mei L, Walker DH, Ren J, Wang Y, Yu XJ. Person-to-person transmission of severe fever with thrombocytopenia syndrome virus. Vector Borne Zoonotic Dis (Larchmont, NY). 2012;12(2):156-60.

8. Chen H, Hu K, Zou J, Xiao J. A cluster of cases of human-to-human transmission caused by severe fever with thrombocytopenia syndrome bunyavirus. Int J Infect Dis. 2013;17(3):e206-8.

9. Tang X, Wu W, Wang H, Du Y, Liu L, Kang K, Huang X, Ma H, Mu F, Zhang S, et al. Human-to-human transmission of severe fever with thrombocytopenia syndrome bunyavirus through contact with infectious blood. J Infect Dis. 2013;207(5):736-9.

10. Jiang XL, Zhang S, Jiang M, Bi ZQ, Liang MF, Ding SJ, Wang SW, Liu JY, Zhou SQ, Zhang XM, et al. A cluster of person-to-person transmission cases caused by SFTS virus in Penglai, China. Clin Microbiol Infect. 2015;21(3):274-9.

11. Gu YF, Qu XL, Liu QH, Guo SM, Wang MY. Person-to-person transmission of severe fever with thrombocytopenia syndrome bunyavirus through secretion and vomitus contact in one family. Rev Med Microbiol. 2014;25(4):123-5.

12. Bao CJ, Qi X, Wang H. A novel bunyavirus in China. N Engl J Med. 2011; 365(9):862-3. author reply 864-865

13. Ma T, Sun JM, Chen LF, Shi XG, Liu K, Gong ZY, Chen J, Zhang R, Ren JP, Jiang JM. A pediatric case of severe fever with thrombocytopenia syndrome in Zhejiang Province, China. J Clin Virol. 2015;72:85-7.

14. Zhang L, Sun J, Yan J, Lv H, Chai C, Sun Y, Shao B, Jiang J, Chen Z, Kortekaas J, et al. Antibodies against severe fever with thrombocytopenia syndrome virus in healthy persons, China, 2013. Emerg Infect Dis. 2014;20(8):1355-7.

15. China National Health and Family Planning Commission. Guideline for prevention and treatment of sever fever with thrombocytopenia syndrome (2010 version). Chin J Clin Infect Dis. 2011;04(4):193-4.

16. Wen HL, Zhao L, Zhai S, Chi Y, Cui F, Wang D, Wang L, Wang Z, Wang Q, Zhang $S$, et al. Severe fever with thrombocytopenia syndrome, Shandong Province, China, 2011. Emerg Infect Dis. 2014;20(1):1-5.
17. Zhao L, Zhai S, Wen H, Cui F, Chi Y, Wang L, Xue F, Wang Q, Wang Z, Zhang $S$, et al. Severe fever with thrombocytopenia syndrome virus, Shandong Province, China. Emerg Infect Dis. 2012;18(6):963-5.

18. Ding F, Guan XH, Kang K, Ding SJ, Huang LY, Xing XS, Sha S, Liu L, Wang XJ, Zhang $X M$, et al. Risk factors for bunyavirus-associated severe fever with thrombocytopenia syndrome, china. PLoS Negl Trop Dis. 2014;8(10):e3267.

19. HUO YY, YAO LY. Failures of infectious disease reporting: analyses and countermeasures. Chin J Nosocomiology. 2004;14(5):515-6.

20. Song $L Z$, Xu AQ, Xiao ZK, Wang AL, Xu Q, Zhang L, Li MS, Zhu CT, Pan YS, $\mathrm{Zj} \mathrm{G}$, et al. A sampling investigation on measles failed reporting in Shandong Province. Chin J Vaccines Immunization. 2000;6(2):88-90.

21. Li JR, Shi XY, Lan MH, Song ZP. Unreported hospital infection: analysis and countermeasures. Chin J Nosocomiology. 2006;16(10):1143-5.

22. Huang $X$, Zhang $Z$, Jin $G$, Wang $X$, Tan C, Yin H, Wang S. Presence of Antibodies against Severe Fever with Thrombocytopenia Syndrome Virus in Non-endemic Areas, China. Jpn J Infect Dis. 2017;70:248-51.

23. Guo CT, Lu QB, Ding SJ, Hu CY, Hu JG, Wo Y, Fan YD, Wang XJ, Qin SL, Cui $\mathrm{N}$, et al. Epidemiological and clinical characteristics of severe fever with thrombocytopenia syndrome (SFTS) in China: an integrated data analysis. Epidemiol Infect. 2016;144(6):1345-54.

24. Hu C, Guo C, Yang Z, Wang L, Hu J, Qin S, Cui N, Peng W, Liu K, Liu W, et al. The severe fever with thrombocytopenia syndrome bunyavirus (SFTSV) antibody in a highly endemic region from 2011 to 2013: a comparative serological study. Am J Trop Med Hyg. 2015;92(3):479-81.

25. xiaoli $D$, jianbo Z. Survey on the infectious status of population with severe fever with thrombocytopenia syndrome bunyavirus in Macheng City, Hubei Province in 2013. Practical Prev Med. 2014;21(06):681-2.

26. Lyu Y, Ding F, Sun J, Xu PP, Hu JY, Xie SY, Li KC, Chang HW, Qin W, Yu L, et al. Seroprevalence and risk factors of severe fever with thrombocytopenia syndrome virus infection in endemic areas. Infect Dis (Lond). 2016;48(7):544-9.

27. Ding $S$, Niu G, Xu X, Li J, Zhang X, Yin H, Zhang N, Jiang X, Wang S, Liang $M$, et al. Age is a critical risk factor for severe fever with thrombocytopenia syndrome. PLoS One. 2014;9(11):e111736.

28. Liang S, Bao C, Zhou M, Hu J, Tang F, Guo X, Jiao Y, Zhang W, Luo P, Li L, et al. Seroprevalence and risk factors for severe fever with thrombocytopenia syndrome virus infection in Jiangsu Province, China, 2011. Am J Trop Med Hyg. 2014;90(2):256-9.

29. Liu Y, Sun TT, Zhang J, Wang ZJ, Yao WQ, Zhao Z. Three methods for detecting severe fever with thrombocytopenia syndrome bunyavirus. Chin J Zoonoses. 2014;30(11):1129-32.

30. Du YH, Huang XY, Wang HF, You AG, Kang K, Chen HM, Xu BL. Comparison on real-time PCR and ELISA methods in detection of severe fever with thrombocytopenia syndrome (SFTS) cases. Chin J Zoonoses. 2013;29(1):101-4.

31. Sun Y, Liang M, Qu J, Jin C, Zhang Q, Li J, Jiang X, Wang Q, Lu J, Gu W, et al. Early diagnosis of novel SFTS bunyavirus infection by quantitative realtime RT-PCR assay. J Clin Virol. 2012;53(1):48-53.

32. Yang ZD, Hu JG, Lu QB, Guo CT, Cui N, Peng W, Wang LY, Qin SL, Wang HY, Zhang PH, et al. The prospective evaluation of viral loads in patients with severe fever with thrombocytopenia syndrome. J Clin Virol. 2016;78:123-8.

33. Lu QB, Cui N, Hu JG, Chen WW, Xu W, Li H, Zhang XA, Ly H, Liu W, Cao WC. Characterization of immunological responses in patients with severe fever with thrombocytopenia syndrome: a cohort study in China. Vaccine. 2015;33(10):1250-5.

34. $\mathrm{dx}$ L. Fever with thormbocytopenia associated with a novel Bunyavirus in China. Chin J Exp Clin Virol. 2011;25(2):81-4.

\section{Submit your next manuscript to BioMed Central and we will help you at every step:}

- We accept pre-submission inquiries

- Our selector tool helps you to find the most relevant journal

- We provide round the clock customer support

- Convenient online submission

- Thorough peer review

- Inclusion in PubMed and all major indexing services

- Maximum visibility for your research

Submit your manuscript at www.biomedcentral.com/submit
Biomed Central 